\title{
Honoré de Balzac, La Commedia umana
}

\section{Marco Stupazzoni}

\section{(2) OpenEdition}

\section{Journals}

\section{Edizione digitale}

URL: http://journals.openedition.org/studifrancesi/9272

DOI: ERREUR PDO dans /localdata/www-bin/Core/Core/Db/Db.class.php L.34 : SQLSTATE[HY000]

[2006] MySQL server has gone away

ISSN: 2421-5856

\section{Editore}

Rosenberg \& Sellier

\section{Edizione cartacea}

Data di pubblicazione: 1 juin 2008

Paginazione: 204-205

ISSN: 0039-2944

\section{Notizia bibliografica digitale}

Marco Stupazzoni, «Honoré de Balzac, La Commedia umana», Studi Francesi [Online], 154 (LII | I) | 2008, online dal 30 novembre 2015, consultato il 07 janvier 2021. URL: http://journals.openedition.org/ studifrancesi/9272 ; DOI: https://doi.org/ERREUR PDO dans /localdata/www-bin/Core/Core/Db/ Db.class.php L.34 : SQLSTATE[HY000] [2006] MySQL server has gone away

Questo documento è stato generato automaticamente il 7 janvier 2021.

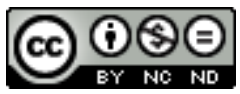

Studi Francesi è distribuita con Licenza Creative Commons Attribuzione - Non commerciale - Non opere derivate 4.0 Internazionale. 


\title{
Honoré de Balzac, La Commedia
}

\section{umana}

\author{
Marco Stupazzoni
}

\section{NOTIZIA}

HONORÉ DE BALZAC, La Commedia umana, scelta e introduzioni di Mariolina BONGIOVANNI BERTINI, Milano, Arnoldo Mondadori Editore, 2005 («I Meridiani»), vol. II, pp. 1831.

1 Nella sterminata e cromaticamente intensa geografia narrativa della Comédie humaine, Illusions perdues e Splendeurs et misères des courtisanes rappresentano sicuramente, per l'eccezionale modernità del loro spessore letterario e ideologico, due tra le 'œuvres capitales' più esteticamente innovative dell'intero ciclo romanzesco balzachiano.

2 Questo secondo volume de La Commedia umana, curato, come il primo volume edito nel 1994, da M. Bongiovanni Bertini per «I Meridiani» di Arnoldo Mondadori, presenta le traduzioni integrali delle due opere di Balzac: D. Selvatico Estense e G. Mezzanotte hanno curato la versione italiana di Illusions perdues, mentre, per quel che riguarda Splendeurs et misères des courtisanes, il testo di riferimento è quello di Marise Ferro del 1961 (Torino, Einaudi) opportunamente rivisto per l'occasione. Prezioso è l'apparato delle note ai testi di Claudia Moro particolarmente utile al lettore italiano per orientarsi nella fitta selva delle citazioni e delle allusioni letterarie, storico-geografiche e politiche di non sempre facile e immediata comprensione.

3 L'«oltraggiosa e contraddittoria modernità» (p. 9) di cui parla M. Bongiovanni Bertini a proposito di Illusions perdues si spiega con il carattere polifonico delle strutture letterarie e dei registri narrativi che informano il tessuto romanzesco dell'opera. Nonostante la caotica frenesia che caratterizza il suo metodo di lavoro (e che non gli consentirà di avere sotto gli occhi una versione complessiva del proprio testo), Balzac riesce ad imprimere ad Illusions perdues i caratteri e le forme, in miniatura, di «quella nebulosa in espansione che è La Comédie humaine» (p. 33) presentando la sua opera come «insostituibile 'effetto di reale' [...] e come spregiudicata adozione del principio tutto 
irrealistico della suspense [...] ereditato dai palcoscenici del mélodrame» (p.9). Particolarmente significativa è, nel romanzo, l'immagine simbolica di Angoulême e la sua trasfigurazione letteraria secondo una logica lontana dal realismo referenziale; esemplare, da una prospettiva diversa, è la genesi de La Torpille, «uno degli esempi più impressionanti della sovrana disinvoltura con la quale Balzac rifiuta il dogma saintebeuviano della 'continuità' del racconto» (p. 23). Ma Illusions perdues è soprattutto il 'roman d'apprentissage' di Lucien all'interno dei tortuosi ed insidiosi labirinti del mondo letterario e giornalistico parigini. Proprio nel trattamento della poesia e del linguaggio giornalistico, la polifonia non solo tragica, ma ironica di Illusions perdues restituisce nel suo insieme «il gusto di un'epoca precisa con la sua folla di stereotipi, tic, manierismi ed effimere mitologie» e svela una pluralità di prospettive che esaltano «il carattere poliedrico del tema affrontato» e ne illuminano «sotto angoli diversi le molteplici sfaccettature» (pp. 43-44).

4 Soltanto pochi critici (e si tratta, in particolare, di scrittori quali Proust e James) hanno colto nella «struttura policentrica» del romanzo balzachiano il suo carattere esemplare. Trascurato dalla critica ottocentesca (Taine, Lanson, Brunetière), rivalutato da Lukàcs come «poema tragico che tratta della 'capitalizzazione dello spirito'» (p. 65), Illusions perdues ha avuto, proprio grazie a Proust e a James, la sua illuminante consacrazione a capolavoro della modernità attraverso, da un lato, la celebrazione di Vautrin come «genio del romanzo» (p. 70); dall'altro, grazie allo «smantellamento dell'icona del Balzac realista» (p. 72) per il carattere poliedrico e la forza inesauribile dell'opera in cui si trovano esaltate (cfr. a questo proposito gli studi di Picon e Chollet) le sue componenti mitiche e fantastiche.

In questa prospettiva storico-letteraria di vasto respiro dove la realtà romanzesca balzachiana sfugge a qualsiasi rigido confronto con un referente esterno al testo, si colloca a pieno titolo Splendeurs et misères des courtisanes, un'opera epica, la cui storia accidentata, complessa e irregolare porta alla luce, erodendone in profondità le fondamenta, la prosaica e contraddittoria realtà parigina. Ancora una volta, qui come in Illusions perdues, è attraverso la figura di Vautrin, «il genio polimorfo e decifratore della forma romanzo» (p. 84) che Balzac svela un orizzonte letterario che «rilancia la narrazione e la prolunga verso nuovi sviluppi» (p. 84). L'ambigua natura proteiforme di questo personaggio - che in fondo non è altro che la prerogativa irrinunciabile del romanzo come genere - e la sua ironia sacrilega introducono nella narrazione «il fermento di un dubbio sistematico e disgregatore»: è, osserva bene la curatrice, «l'inflessione di una voce non autoriale, ma paradossalmente autorevole, che contribuisce in modo decisivo alla polifonia del testo» (p.84) e alla rinascita del codice romanzesco come forma del mito e specchio di una modernità liberata dai vincoli della tradizione classica. 